\title{
Self-cleaning Hydrophobic Nanocoating on Glass: a Scalable Manufacturing Process
}

\author{
Surendra Maharjan \\ Kang-Shyang Liao \\ University of Houston \\ Alexander J. Wang \\ University of Houston
}

University of Houston - Main

See next page for additional authors

Follow this and additional works at: https://arrow.tudublin.ie/nanolart

Part of the Physical Sciences and Mathematics Commons

\section{Recommended Citation}

Maharjan, S. et al (2019). Self-cleaning hydrophobic nanocoating on glass: a scalable manufacturing process. Materials Chemistry \& Physics, 239, 122000

This Article is brought to you for free and open access by the NanoLab at ARROW@TU Dublin. It has been accepted for inclusion in Articles by an authorized administrator of ARROW@TU Dublin. For more information, please contact arrow.admin@tudublin.ie, aisling.coyne@tudublin.ie,gerard.connolly@tudublin.ie.

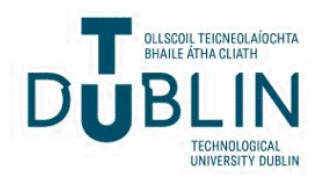




\section{Authors}

Surendra Maharjan, Kang-Shyang Liao, Alexander J. Wang, Killian Barton, Amrita Haldar, Nigel J. Alley, Hugh J. Byrne, and Seamus A. Curran 


\title{
Self-Cleaning Hydrophobic Nanocoating on Glass: \\ A Scalable Manufacturing Process
}

\author{
Surendra Maharjan ${ }^{1,2}$, Kang-Shyang Liao ${ }^{1,2}$, Alexander J. Wang ${ }^{1,2}$, Killian Barton ${ }^{1,3}$, Amrita \\ Haldar $^{1}$, Nigel J. Alley ${ }^{1}$, Hugh J. Byrne ${ }^{3}$, Seamus A. Curran ${ }^{1,2}$ \\ ${ }^{1}$ Institute for NanoEnergy, Department of Physics, University of Houston, Houston, TX 77204, USA \\ ${ }^{2}$ Integricote, Inc. (formerly known as C-Voltaics, Inc.), Houston, TX 77023, USA \\ ${ }^{3}$ FOCAS Research Institute, Technological University Dublin, Kevin Street, Dublin 8, Ireland
}

\begin{abstract}
A method of forming a self-cleaning hydrophobic coating (SCHN) on glass substrates utilizing a scalable manufacturing process is described. The process initiates with roughening of planar glass surfaces using diamond micro-/nano-particle abrasives, which creates microscopic tortuous grooves. After cleaning the substrates, the roughened surface is vapor deposited with trichloro(1H,1H,2H,2H-perfluorooctyl)silane (TCPFOS) under enclosure with controlled humidity. TCPFOS chemically binds with the substrate via covalent linkage. Due to the greatly reduced surface tension between water and the self-cleaning surface, the water droplet slides down leaving no trail (sliding angle of $14^{\circ}$ for $0.1 \mathrm{~mL}$ water droplet). Due to the reduced adhesion of dirt to the self-cleaning surface, the dirt particles are washed away by sliding or rolling water droplets. The SCHN shows no change in transmission as compared to the original glass substrate. The coating is resistant to multiple environmental factors including: abrasion cycles, acid rain $(\mathrm{pH}=$ 3), saline exposure $(10 \% \mathrm{w} / \mathrm{v})$, and extreme temperature cycling $\left(-10\right.$ to $\left.60{ }^{\circ} \mathrm{C}\right)$.

Keywords: Self-cleaning, Hydrophobic, Nanocoating, Perfluoroalkylsilane, Manufacturing

\section{Introduction}


Solar energy is among the most reliable sources of renewable energy that can be harvested on Earth. Many types of research associated with photovoltaic materials and device fabrication techniques have been extensively studied to enhance the performance of solar cells. Solar power plant output performance can be greatly impacted by the accumulation of dirt or dust on the protective glass layer that shields the active solar cells from the elements. In the presence of dust or dirt, solar irradiance is likely to be reflected and scattered by dust particles, inhibiting light transmission to the solar cell, which subsequently causes the detrimental effects on photovoltaic cell output. According to the dust distribution pattern study, North Africa and the Middle East are identified to have the severe dust accumulation zones in the world [1][2][3][4]. For example, $\mathrm{PM}_{10}$ (defined as particulate matter of diameter $10 \mu \mathrm{m}$ or less) concentrations in Sudan and Saudi Arabia were recorded about 140 and $100 \mu \mathrm{g} / \mathrm{m}^{3}$ respectively in 2010 which were significantly higher compared to $25 \mu \mathrm{g} / \mathrm{m}^{3}$ of the United States [4]. A feasible solution to this issue is a self-cleaning hydrophobic coating (SCHN) for glass that prevents the accumulation of dirt and dust particles on the surfaces of solar panels. The objective of this study is to develop a technique and process to mass-produce glass panels coated with SCHN. The surface topography of glass, while a planar structure, is comprised of many microgrooves and microstructures with varying degrees of -OH functional group distribution. Consequently, the glass allows water to wet the surface, which attracts dust and dirt particles that eventually become stuck in the groves and cracks of the microstructures of glass - over time, cleaning grows more cumbersome with each iteration, often necessitating mechanical abrasion with caustic chemicals.

Soiling and shading of solar panels are a major problem worldwide, affecting the power output, reliability, and lifetime of solar panels. Shading and soiling account for up to $5 \%$ power loss in solar panels yearly in the US - in China, it is far greater at 26\% per annum [5][6]. Shading during a certain time of year in Saudi Arabia and North Africa can result in 30-65\% loss in power 
[1][7]. To remove light dust particles requires at least $20 \mathrm{~mm}$ (or $3 / 4$ inches) of heavy rainfall; with any less, the rain will cause dust particles to stick rather than to be removed [5]. In some instances, the damage can be so severe that the soiling can cause actual damage to the silicon inside the solar panel due to hotspots [8]. Soiling will no doubt alter the power output and lifetime of the solar installation, which has a direct effect on reliability and warranties (lifetime) of panels. Salt water, available in many places where fresh water itself is scarce and very valuable, conventionally cannot be used for cleaning as it leaves salt particles behind, inducing hotspots and shading. Fundamentally, solar panels will naturally lose power over time due to degrading efficiency. Dirt and dust will have an additional negative impact on power output that can only be mitigated by keeping the protective glass surface clean.

One of the most important aspects of research associated with surface chemistry is the wetting behavior of solid surfaces by the liquids in contact. In recent years, considerable amount of research interests in superhydrophobic and self-cleaning surfaces/materials have been identified owing largely to their potential real world applications and the revived enthusiasm to understand the fundamental underlying of these phenomena [9][10][11][12][13][14][15]. Unfortunately, the terms "superhydrophobic" and "self-cleaning" are generally poorly defined and can cause confusion. For example, a superhydrophobic surface is usually "defined to have a minimum static contact angle of $150^{\circ}$ and maximum sliding angle of $5^{\circ}$, but these numbers are inherently imprecise and somewhat arbitrary. In addition, the terms "superhydrophobic" and "self-cleaning" are sometimes used interchangeably, but fundamentally, they describe two totally different phenomena.

A self-cleaning phenomenon is a situation when water drops of a set volume/mass can undergo sliding, rolling, or both when the self-cleaning substrate is titled beyond the critical angle. The water droplets slide down the surface leaving no trail by virtue of the significant reduction in 
surface tension between water droplets and self-cleaning surface. As a result, dust particles are easily washed off when water droplets roll/slide down the self-cleaning surface [9].

Self-cleaning surfaces are generally manufactured in two following ways: through the creation of hierarchial micro/nanostructures on hydrophobic surface or through the chemical modification of micro/nanostructured surface with molecules having low surface free energies. Man-made self-cleaning coatings use complicated deposition methods, such as chemical vapor deposition, layer-by-layer assembly, and micro-patterning which are arguably not suited for a deposition to large surfaces [16][17][18][19]. The method disclosed herein overcomes this limitation. This is achieved by first roughing the substrate surface and subsequently coating the roughed surface with appropriate chemical agents, such as fluoroalkylsilanes.

\section{Experimental Section}

\subsection{Materials}

Trichloro(1H,1H,2H,2H-perfluorooctyl)silane (TCPFOS) (97\%) and isopropanol were purchased from Sigma-Aldrich and were used without any further modification. Nitric Acid (ACS reagent, 70\%) was purchased from Sigma-Aldrich and was diluted down with deionized water to achieve a $\mathrm{pH}$ of 3 . Polycrystalline $0.1 \mu \mathrm{m}$ diamond suspension $\left(\mathrm{MetaDi}^{\circledR}\right)$ and polishing cloth (MasterTex, PSA, 8 in) were purchased from Buehler. Saline solution $(10 \% \mathrm{w} / \mathrm{v})$ was prepared by dissolving $100 \mathrm{~g}$ of $\mathrm{NaCl}$ in $1000 \mathrm{~mL}$ of water.

\subsection{Materials Characterization}

UV-Vis-NIR spectra were acquired using an Ocean Optics 2000 HR spectrometer with a deuterium/halogen light source (Ocean Optics DH-2000) to study optical transmission properties of pristine and TCPFOS coated glass. An Asylum MFP-3D-BIO Atomic Force Microscope was used to obtain insight on the surface topography of TCPFOS coated glass. 
Third party durability tests of TCPFOS coating were performed by PPG Industries, Inc., who also supplied glass coupons that were marked to indicate the tint side of the glass. The coating was applied to the air side of the coupons, where PPG would perform condensing humidity exposure and UV exposure. The performance of the coating was ultimately judged by the change in the contact angle throughout the duration of the test. At least three specimens were used for each test, where the data points for each test were calculated from averaging 5 separate manually measured contact angles for each specimen. Condensing Humidity Exposure: Three 2" x 6" coupons were tested in a Q-Panel Cleveland Condensation Tester at a temperature of $60{ }^{\circ} \mathrm{C}$ and a relative humidity of $100 \%$. UV Exposure: Four 3" x 4" coupons were subjected to a QUV accelerated weathering tester; model QUV 1 SE (Q-Lab Corporation) with UVB-313 lamps on a Solar Eye irradiance controller. The test comprised of a combination of UV and condensation exposure with the following cycle: eight hours of UV at $0.49 \mathrm{~W} / \mathrm{m}^{2}$ and $70{ }^{\circ} \mathrm{C}$, followed by four hours of condensation at $50^{\circ} \mathrm{C}$. The UV sensors were calibrated at $500 \mathrm{~h}$ intervals.

\subsection{Substrate Preparation and Coating Application}

A pre-cleaned plain glass slide (Corning) is polished for 3 minutes with a $0.1 \mu \mathrm{m}$ polycrystalline diamond suspension (MetaDi, Buehler) using a polishing cloth (MasterTex, Buehler) attached to a mechanical polisher. The polished glass is cleaned with soap water and washed with de-ionized water and isopropanol thoroughly. After drying, the glass is transferred into a controlled environmental enclosure with a relative humidity level of $16 \%$ and exposed to the vapor of TCPFOS generated by heating the chemical in a quartz vessel on a hotplate. After 20 minutes, the glass is removed from the enclosure and the surface is cleaned with isopropanol thoroughly.

\section{Results and Discussion}

\subsection{Application Process of Self-cleaning Hydrophobic Coating}


In this work, a self-cleaning surface on glass substrates is produced by abrading the substrate (abrasive I) to generate microscopic, random patterned grooves. Critical angle requirements for different applications may vary dramatically, such as $<90^{\circ}$ for windows, roughly $30^{\circ}$ for solar panels and automobile windshields, and roughly $10^{\circ}$ for sunroofs. Therefore, the substrate might need to be roughened with a second abrasive (abrasive II) to generate secondary microscopic feature as illustrated in Fig. 1a. The preferred choice of abrasive is such that the hardness of the abrasive (e.g., polycrystalline diamond solution, Moh's scale of hardness $=10$ ) is greater than that of substrate (glass, Moh's scale of hardness $=5.5$ ) [20], and preferred abrasive grain sizes range from $10 \mathrm{~nm}$ to $10 \mathrm{~mm}$. After cleaning, the resulting surface is then treated with a hydrophobic chemical agent, which renders the surface hydrophobic and also generates a nanoscopic topography. To generate the desired nanoscopic topography, a well-controlled environment is needed for the hydrophobic treatment. A schematic illustration of the enclosure Fig. $1 \mathrm{~b}$ illustrated the enclosure for conducting the hydrophobic treatment on a large substrate such as a solar panel. The panel to be treated is inserted into the treatment container with the help of a conveyor belt. A small amount of TCPFOS is placed on a glass petri dish, and $80{ }^{\circ} \mathrm{C}$ solution temperature is maintained using a heating element (hot plate). In order to generate nanoscopic topography, extra water molecules may be needed to promote polymerization of the hydrophobic chemicals. Hence, the humidity level is maintained inside the container using a dehumidifier to be about $16 \%$ of related humidity. An extra opening on top is used for ventilation. After the reaction between the hydrophobic chemicals and the surface is completed, the excess amount of the chemical solution is removed and the surface is washed with isopropanol. The resulting substrate is removed from the enclosure and dried under ambient conditions. The mechanism by which TCPFOS covalently links with a glass substrate is presented in Fig. 1c [21].

The resulting self-cleaning coatings show no apparent loss of transmission of the visible light to the substrate. Such self-cleaning coatings are therefore well suited for a range of 
applications including the self-cleaning of solar panels. Other applications include but are not limited to products that require regular cleaning of their surface in order to maintain their proper functions, such as for example automobile windshields, windows, and sunroofs. The self-cleaning coatings may also have the desired properties for corrosion protection and anti-fouling of metallic structures.
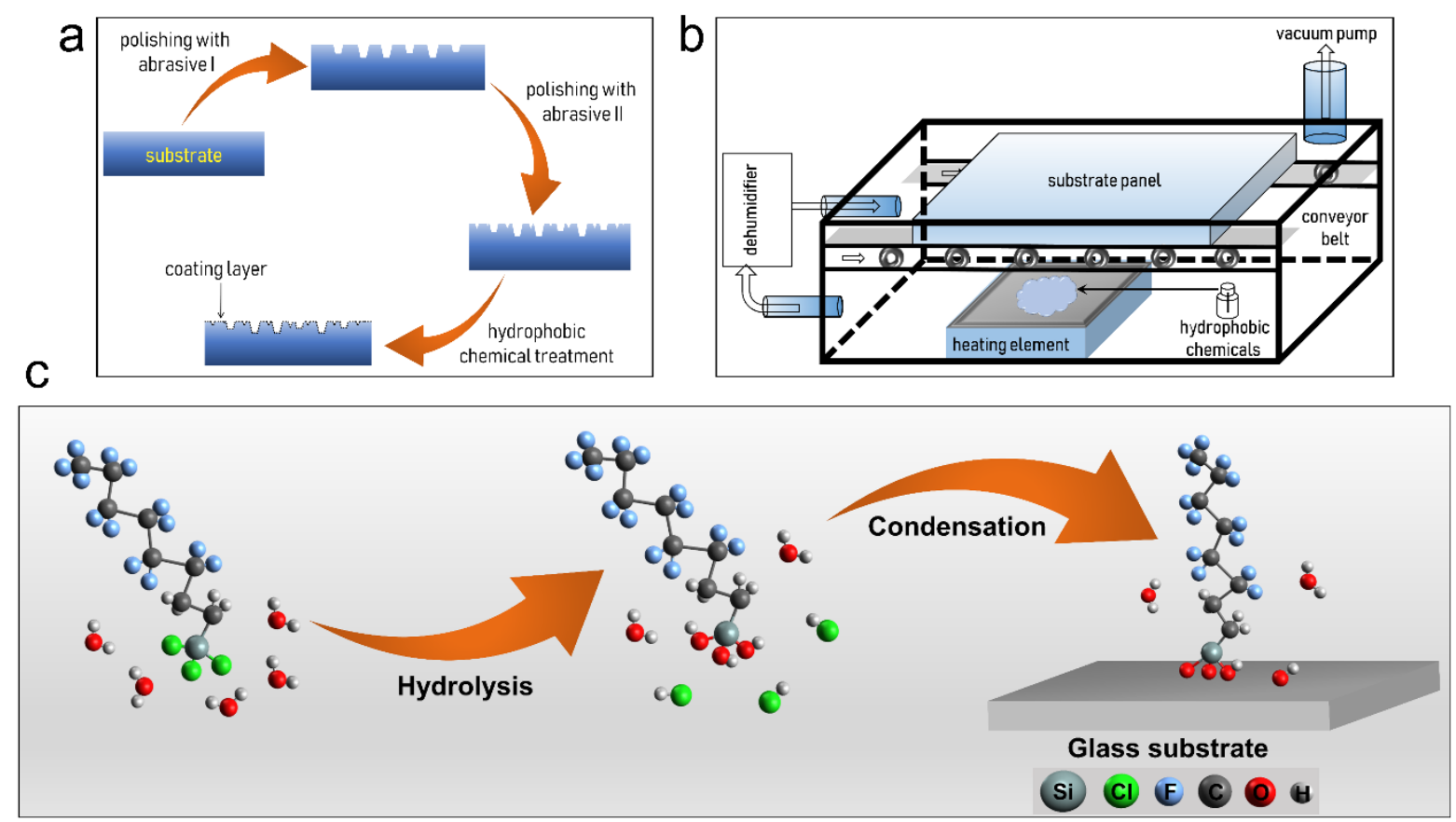

Fig. 1. (a) Schematic illustration of the self-cleaning hydrophobic coating application procedure,

(b) the enclosure for conducting the hydrophobic treatment, and (c) generalized illustration of a reaction mechanism by which TCPFOS covalently links to a glass substrate.

\subsection{Surface Topography}

Surface topography of TCPFOS coated glass was studied using atomic force microscopy (AFM) techniques. Fig. 2a and $2 \mathrm{~b}$ show phase contrast and tapping-mode topography micrographs of TCFOS coated glass, respectively. The micro-/nano-scale grooves resulting from mechanical abrasion in tandem with a polycrystalline diamond abrading suspension. These largely rectilinear intersecting grooves are highly desired to enhance the adhesion of TCPFOS molecules to the glass surface as well as generating a more uniformly roughened surface. Fig. $2 \mathrm{c}$ shows the height profile 
plot of the TCPFOS coating on the glass, where we can see the coating thickness ranges between 1-10 $\mathrm{nm}$. This reveals the high uniformity in the thickness of the TCPFOS coating. In addition, the lack of contrast between AFM micrographs in Fig. $2 a$ and $2 b$ further support the sub-10 nm thickness of the coating. The white artifacts appeared on AFM images may be due to the presence of residual abrasives.

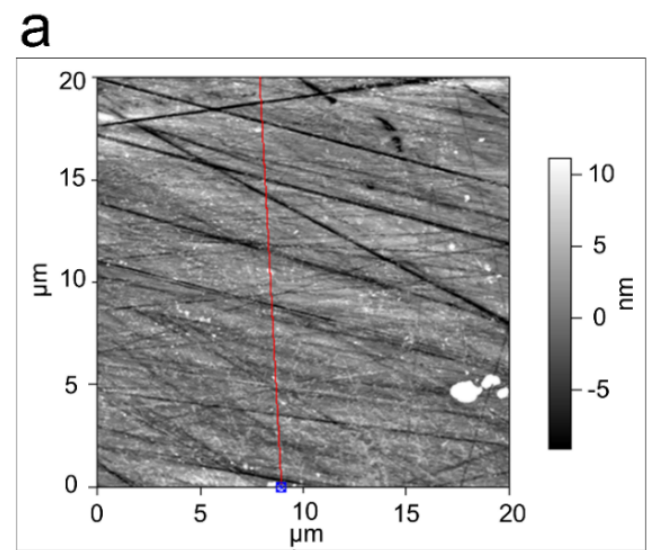

b
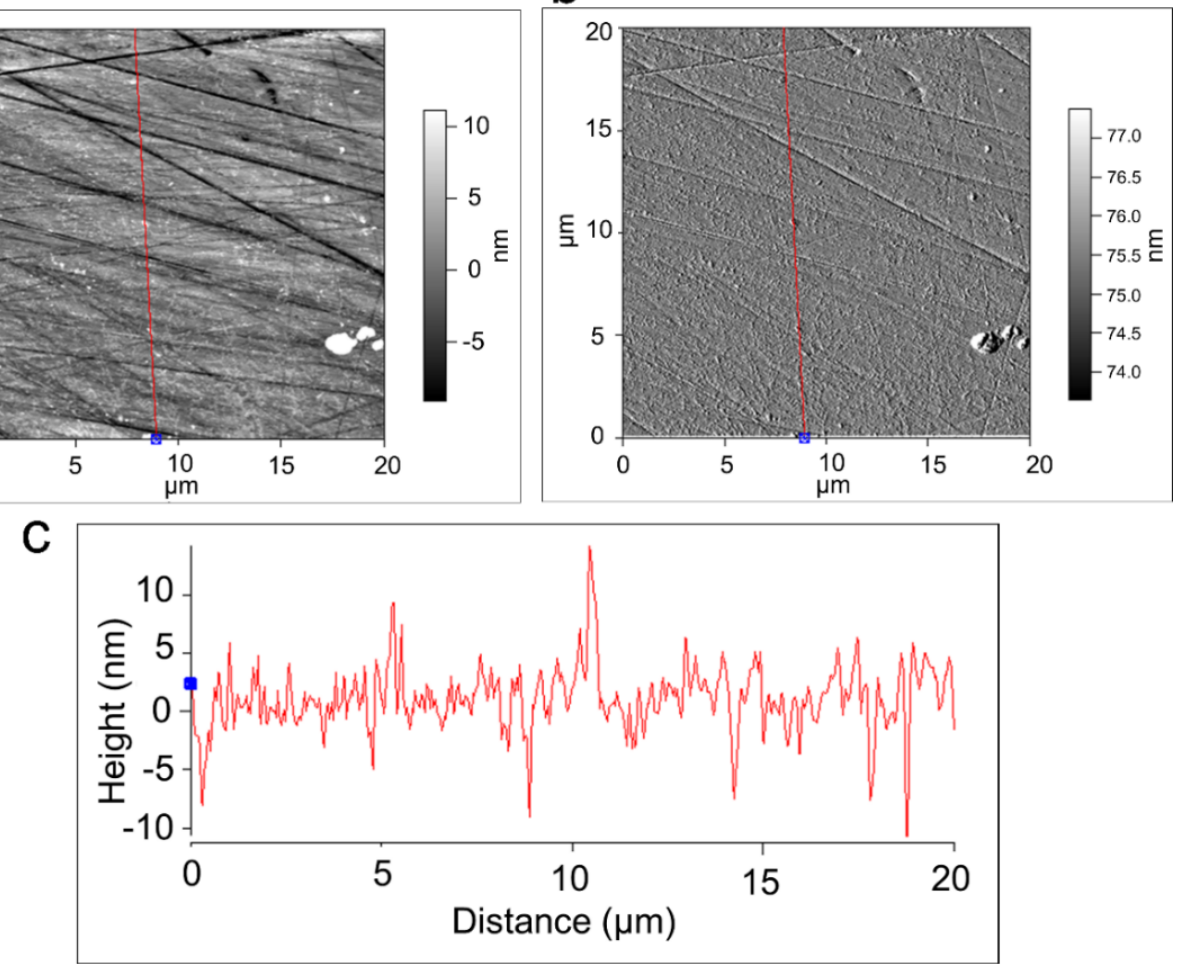

Fig. 2. AFM study of TCPFOS coated glass (a) phase contrast image, (b) tapping-mode topography image, and (c) height profile evaluation of coating.

\subsection{Effect of Self-cleaning Coating on Light Penetration}

We did not observe any apparent optical differences between pristine and TCPFOS coated glass panels when viewed side-by-side. Fig. 3 shows the UV-Vis-NIR transmission spectra of pristine and TCPFOS coated glass samples, where both spectra fairly overlapped with each other in the range of 300-1000 nm. Due to the thin nature of the coating layer coupled with no UV-Vis- 
NIR light absorption means chemisorbed TCPFOS layers do not block or hinder any light passing through to the solar cells and thus will not cause any shading problems.

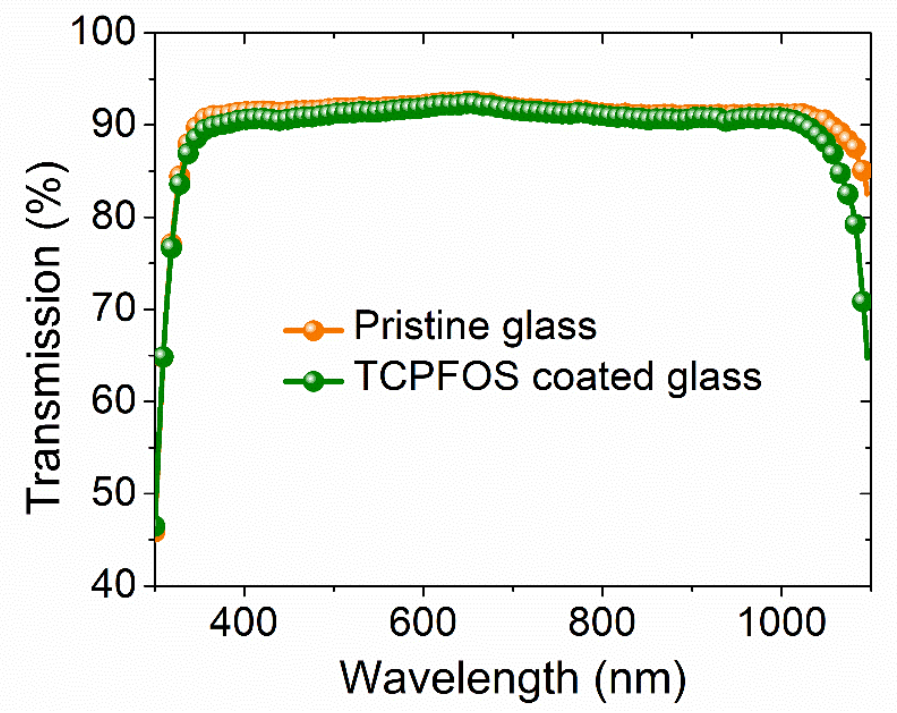

Fig. 3. UV-Vis-NIR transmission spectra of pristine and TCPFOS coated glass panels.

\subsection{Self-cleaning Property of TCPFOS Coating}

Here we describe a phenomenon where a water droplet slides down a tilted substrate surface that has been previously treated with a "self-cleaning" coating. Due to the greatly reduced surface tension between water and the coated surface, the water droplet slides down without any remnant of the droplet adhering to the surface. Fig. 4 a shows the water droplet sliding down the TCPFOS coated solar panel glass without leaving a water trail. In addition, the adhesion between the dust particles and the coated substrate surface is also reduced so the particles are easily washed away by the movement of a water droplet. Fig. 4b shows a water droplet sliding down the TCPFOS coated solar panel glass in the presence of dust particles. This phenomenon allows the force of water to remove the dust and dirt collected on the surfaces of solar panels by gravitationally pushing the soiling to the bottom of the panels, keeping the panel clean.

To demonstrate the effectiveness of dust particle removal using SCHN, an experiment using continuous droplets of water to simulate rainfall or a water sprinkler system dripping from the top of the panel was conducted. Referring to Fig. 4b, cleaning a $1.0 \mathrm{~cm}$ width of accumulated dust 
particles on a standard glass solar panel requires $22 \mathrm{~mL}$ of water when the panel is titled over $30^{\circ}$. On the other hand, a TCPFOS coated glass solar panel requires only $10 \mathrm{~mL}$ of water when the panel is tilted to only $6^{\circ}$.

a

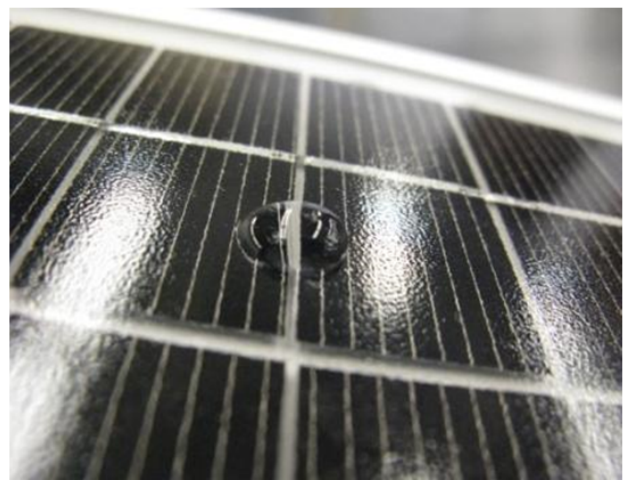

b

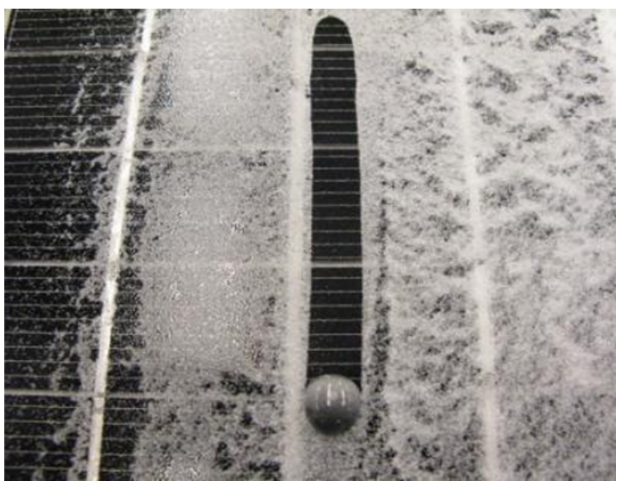

Fig. 4 (a) A water droplet sliding down a TCPFOS coated solar panel (no dirt). (b) A coated solar panel soiled with dust - the water droplet picks up dust when sliding down.

\subsection{Effect of Salt Water on Solar Panels}

Analogous to dust and dirt, salt deposits on solar panel surfaces can greatly impact their lifetime and power output efficiency. During dew formation in the morning, atmospheric dust having soluble/insoluble salts forms micro-salt droplets on solar panel and upon drying, leaves precipitated salt on the panel, which is often not easy to clean and causes shading problems [22][23]. In order to test the effects of salt solutions on deposited TCPFOS coatings, we performed saline resistant tests on both the pristine and TCPFOS coated solar panels (each with area $\sim 1.7$ $\mathrm{m}^{2}$ ). Both pristine and TCPFOS coated glass panels were subjected to drizzling of $500 \mathrm{~mL}$ of $10 \%$ w/v (aq.) saline solution four times a day for 7 days. The TCPFOS coated panel shows little to no salt deposit, maintaining the initial contact angle $\left(104^{\circ}\right)$ unchanged after a week. On the other hand, the pristine panel shows substantial salt deposit, as shown in Fig. 5. 


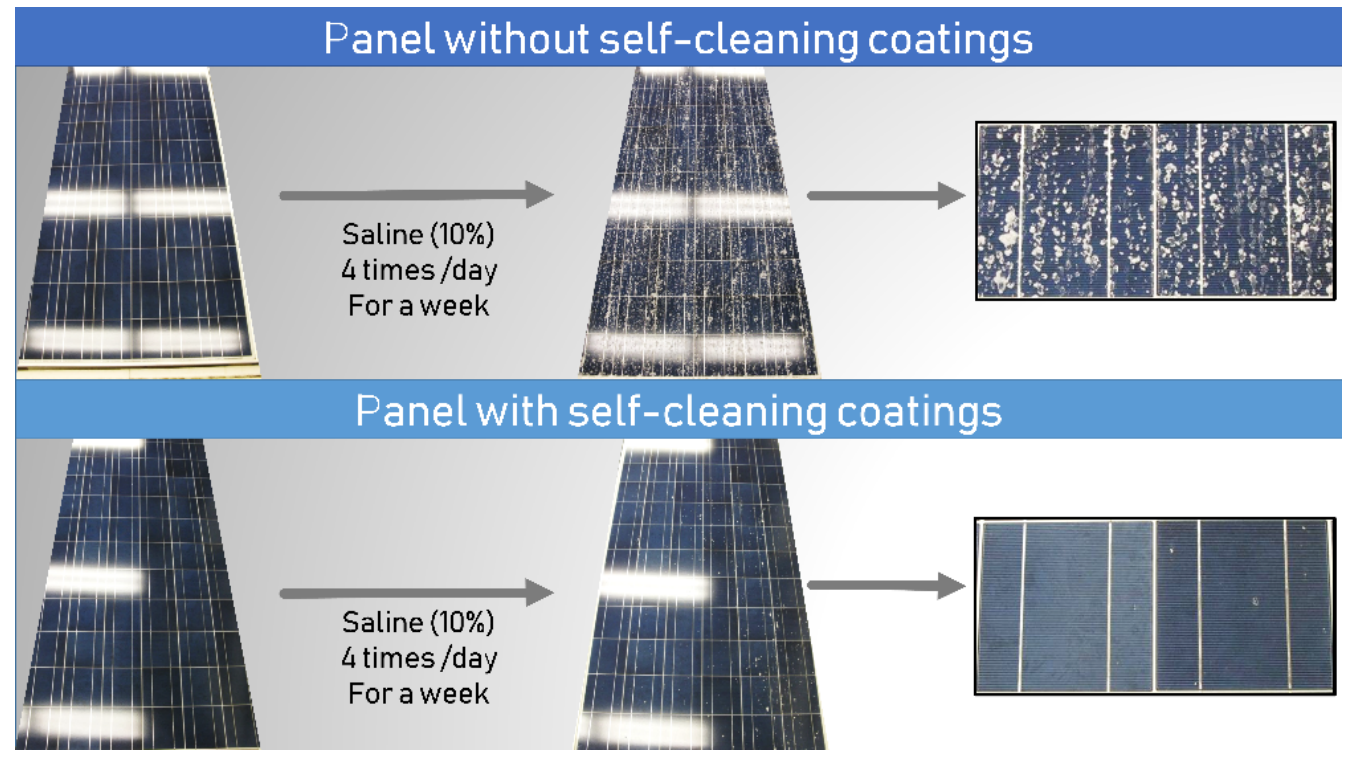

Fig. 5. Saline resistance tests on uncoated and TCPFOS (SCHN) coated solar panels.

\subsection{Impact of Abrasion Studies}

In real world scenarios, surface coatings are inevitably exposed to various elements that cause abrasion and erosion, eventually damaging the coating. The durability of a coating is, therefore, an important factor for an ideal surface coating. To examine SCHN's ability to withstand abrasion, we conducted a test consisting of rubbing the coated panel with a 1.5-inch diameter cotton round pad (SPI Lint Free Cotton Wipes \#5151-SA) loaded with a $500 \mathrm{~g}$ weight traversing a straight path back-and-forth 10,000 times - the abrasion pad was changed every 600 rubs. After 10,000 rub cycles, the water contact angle decreases from $105 \pm 3^{\circ}$ to $98 \pm 3^{\circ}$. The linear trend line of contact angle versus abrasion cycles plot in Fig. 6a shows $\mathrm{a} \sim 3^{\circ}$ decrease / 10,000 rubs. The sliding angle of $0.1 \mathrm{~mL}$ water drop ideally remains the same from $14^{\circ}$ (after treatment) to $15^{\circ}$ (after 10,000 rubs). The static contact angles remain the same (or smaller than the errors of the contact angle measurements). This demonstrates that constant wear on the coatings will not inhibit the hydrophobic action of the coatings. 

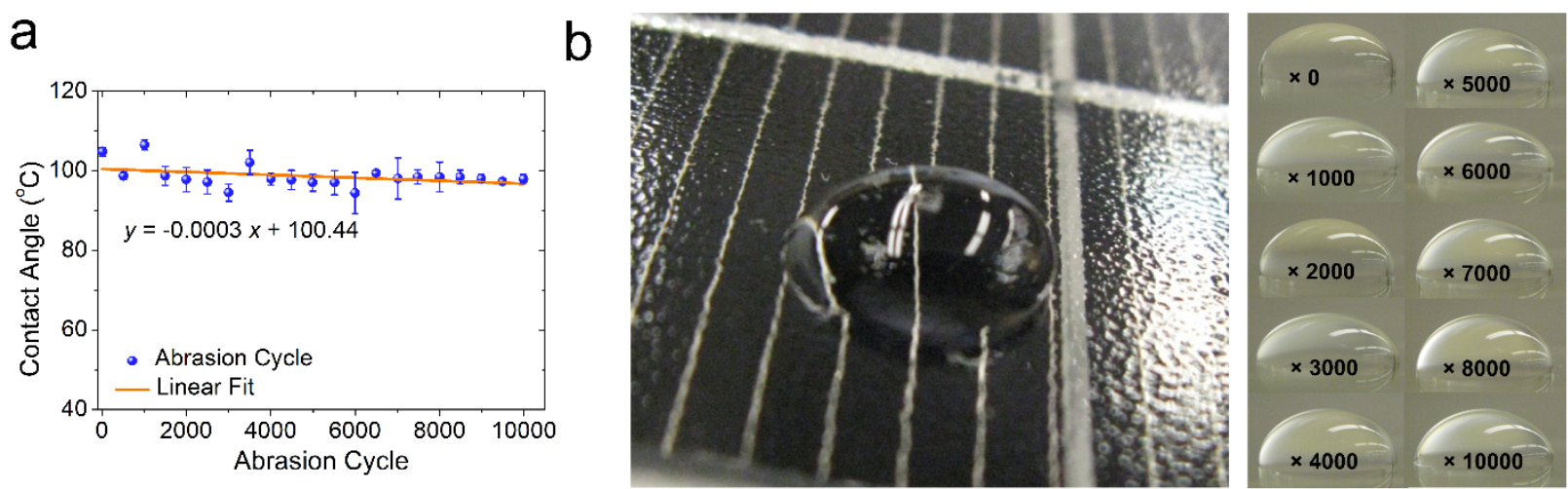

Fig. 6 (a) Impact of abrasion studies (orange line is the linear fit). (b) TCPFOS coated glass shows minimal degradation after 10,000 abrading cycles using a cotton pad with a $0.5 \mathrm{~kg}$ load.

\subsection{Effect of Humidity and UV Exposure}

Durability tests against long-term condensing humidity $\left(100 \% \mathrm{RH}\right.$ at $\left.60{ }^{\circ} \mathrm{C}\right)$ and $\mathrm{UV}$ exposure were independently performed by PPG Industries, Inc. The test results are compared with a current PPG hydrophobic surface treatment (PPG baseline) and typical values measured by PPG for a commercially available rain repellant product for automotive glass. The key measure of failure of a coating is the time at which the water contact angle falls below $60^{\circ}$. At this point, consumers would lose the ability to differentiate a clear advantage of the coating. Fig. 7a and $7 \mathrm{~b}$ show the results of condensing humidity and UV exposure tests.

Condensing humidity test on three TCPFOS coated glass samples performed for a long period of time resulted in a gradual decrease in water contact angle of the coated surface from 105 $\pm 1.5^{\circ}$ to $64.6 \pm 1.5^{\circ}$ in $1,400 \mathrm{~h}$. Coating performance was comparatively far superior to PPG's baseline (400-800 h) and commercially available product $(<100 \mathrm{~h})$.

Likewise, a UV exposure degradation study was carried out on three samples coated with TCPFOS coating. An approximate linear decrease of water contact angle from $107 \pm 1.2^{\circ}$ to $63 \pm$ $1.0^{\circ}$ was monitored during a course of $2,422 \mathrm{~h}$, which is quite remarkable as compared to the performance of PPG's commercially available coating $(<100 \mathrm{~h})$ and comparable to PPG's baseline (2000-3000 h). 

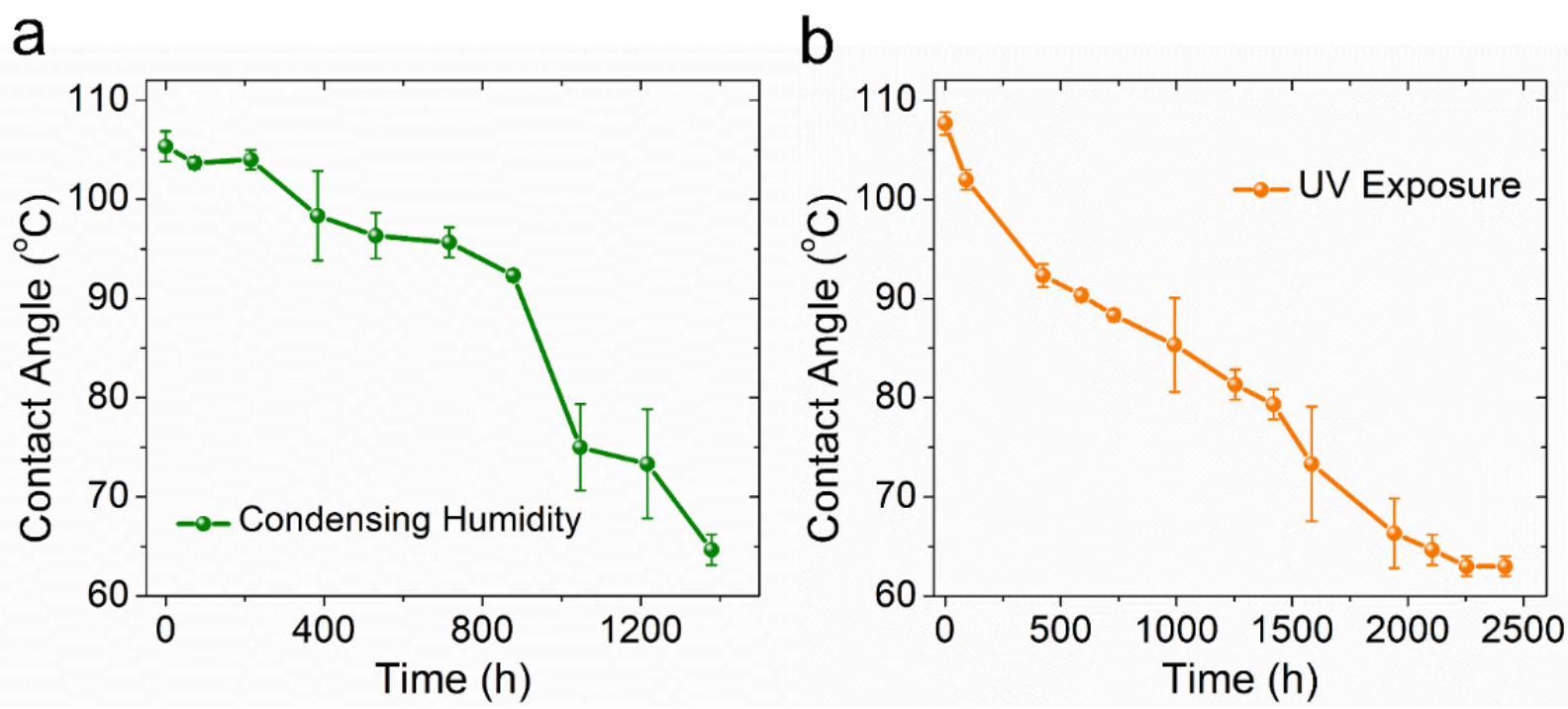

Fig. 7. Durability testing of TCPFOS coating using a) condensing humidity and b) UV exposure tests. The plots are expressed in terms of water contact angle as a function of time

\subsection{Acid Resistance, Temperature Degradation/Tolerance:}

Apart from the aforementioned environmental elements, there are various other factors that can deteriorate the long term durability of environmental surface coatings, such as acidic rain and extreme temperature variations. To simulate exposure to acid rain conditions, the TCPFOS coated glass panel was submerged in a nitric acid solution $(\mathrm{pH}<3)$ at $80{ }^{\circ} \mathrm{C}$ for $30 \mathrm{~min}$. No change in the initial contact angle $\left(104^{\circ}\right)$ was observed after the test. For thermal degradation study under extreme environmental conditions, TCPFOS coated glass panel was tested via multiple heating and cooling cycles at temperatures between -10 and $60{ }^{\circ} \mathrm{C}$. The initial contact angle $\left(104^{\circ}\right)$ remained constant after 12 cycles. In order to study the thermal breakdown temperature of the coating, TCPFOS coated Corning glass slides were heated to $360{ }^{\circ} \mathrm{C}$, where no change in the contact angle of the coated glass was observed (measured after it was cooled to the room temperature). Therefore, the thermal breakdown of the coating was expected to be well above $360{ }^{\circ} \mathrm{C}$. This result agrees with the thermogravimetric studies on TCPFOS done by Kaynak et al. [24]. 
Table 1 presents a summary of results obtained for all tests carried out on SCHN coated glass.

Table 1. Summary of SCHN coated glass test results.

\begin{tabular}{|c|c|}
\hline Specifications & Test Results \\
\hline Critical Sliding Angle & $14^{\circ}(0.1 \mathrm{~mL}$ of water droplet $)$ \\
\hline Transparency & $\begin{array}{l}\text { No change in optical transmission across a range of } 300-1000 \mathrm{~nm} \\
\text { compared to pristine glass }\end{array}$ \\
\hline Abrasion Resistance & $\begin{array}{l}\text { No degradation after } 10,000 \text { rubbing cycles with a } 1.5 \text {-inch diameter } \\
\text { cotton round pad (SPI Lint Free Cotton Wipes } \# 5151 \text {-SA) loaded } \\
\text { with a } 500 \mathrm{~g} \text { weight (traversing a straight path - the pad was changed } \\
\text { every } 600 \text { rubs) }\end{array}$ \\
\hline Saline Resistance & $\begin{array}{l}\text { No degradation after drizzling } 500 \mathrm{~mL} \text { of } 10 \% \text { (aq.) saline solution } \\
\text { four times a day for a week }\end{array}$ \\
\hline Temperature Tolerance & $\begin{array}{l}\text { No degradation after temperature cycling } 12 \text { times between }-10{ }^{\circ} \mathrm{C} \\
\text { and } 60^{\circ} \mathrm{C}\end{array}$ \\
\hline $\begin{array}{l}\text { Thermal Breakdown } \\
\text { Temperature }\end{array}$ & $>360^{\circ} \mathrm{C}$ (Coatings on a Corning glass slide) \\
\hline
\end{tabular}

\section{Conclusions}

We successfully demonstrated a simple and facile process for large-scale production of a robust and transparent self-cleaning hydrophobic coating for glass. The coating exhibits excellent saline resistance, acid resistance, abrasion resistance, and thermal breakdown temperature together with an exceptional critical sliding angle of $14^{\circ}$ for $0.1 \mathrm{~mL}$ of water.

\section{Conflict of interest}

This technology has been licensed and commercialized by Integricote, Inc., Houston, TX, USA. The chemical test results were also provided by Integricote, Inc. which were performed by third party testing facilities.

\section{Corresponding Author}


Surendra Maharjan (smaharjan@uh.edu)

\section{References}

[1] M.R. Maghami, H. Hizam, C. Gomes, M.A. Radzi, M.I. Rezadad, S. Hajighorbani, Power loss due to soiling on solar panel: A review, Renewable and Sustainable Energy Reviews. 59 (2016) 1307-1316. doi:10.1016/j.rser.2016.01.044.

[2] R.R. Cordero, A. Damiani, D. Laroze, S. MacDonell, J. Jorquera, E. Sepúlveda, S. Feron, P. Llanillo, F. Labbe, J. Carrasco, J. Ferrer, G. Torres, Effects of soiling on photovoltaic (PV) modules in the Atacama Desert, Scientific Reports. 8 (2018) 1-14. doi:10.1038/s41598-018-32291-8.

[3] J.R. Caron, B. Littmann, Direct monitoring of energy lost due to soiling on first solar modules in California, IEEE Journal of Photovoltaics. 3 (2013) 336-340. doi:10.1109/JPHOTOV.2012.2216859.

[4] S. Ghazi, A. Sayigh, K. Ip, Dust effect on flat surfaces - A review paper, Renewable and Sustainable Energy Reviews. 33 (2014) 742-751. doi:10.1016/j.rser.2014.02.016.

[5] A. Kimber, L. Mitchell, S. Nogradi, H. Wenger, The effect of soiling on large gridconnected photovoltaic systems in California and the Southwest Region of the United States, Conference Record of the 2006 IEEE 4th World Conference on Photovoltaic Energy Conversion, WCPEC-4. 2 (2007) 2391-2395. doi:10.1109/WCPEC.2006.279690.

[6] H. Jiang, L. Lu, K. Sun, Experimental investigation of the impact of airborne dust deposition on the performance of solar photovoltaic (PV) modules, Atmospheric Environment. 45 (2011) 4299-4304. doi:10.1016/j.atmosenv.2011.04.084.

[7] S. Mekhilef, R. Saidur, M. Kamalisarvestani, Effect of dust, humidity and air velocity on efficiency of photovoltaic cells, Renewable and Sustainable Energy Reviews. 16 (2012) 2920-2925. doi:10.1016/j.rser.2012.02.012.

[8] M.S. Ngan, C.W. Tan, A study of maximum power point tracking algorithms for stand- 
alone photovoltaic systems, 2011 IEEE Applied Power Electronics Colloquium, IAPEC 2011. (2011) 22-27. doi:10.1109/IAPEC.2011.5779863.

[9] Y.Y. Quan, L.Z. Zhang, R.H. Qi, R.R. Cai, Self-cleaning of Surfaces: The role of surface wettability and dust types, Scientific Reports. 6 (2016) 1-12. doi:10.1038/srep38239.

[10] M. Yu, S. Chen, B. Zhang, D. Qiu, S. Cui, Why a lotus-like superhydrophobic surface is self-cleaning? An explanation from surface force measurements and analysis, Langmuir. 30 (2014) 13615-13621. doi:10.1021/la5041272.

[11] P. Cully, F. Karasu, L. Müller, T. Jauzein, Y. Leterrier, Self-cleaning and wear-resistant polymer nanocomposite surfaces, Surface and Coatings Technology. 348 (2018) 111-120. doi:10.1016/j.surfcoat.2018.05.040.

[12] W. Tong, D. Xiong, N. Wang, C. Yan, T. Tian, Green and timesaving fabrication of a superhydrophobic surface and its application to anti-icing, self-cleaning and oil-water separation, Surface and Coatings Technology. 352 (2018) 609-618.

doi:10.1016/j.surfcoat.2018.08.035.

[13] M.T.S. Tavares, A.S.F. Santos, I.M.G. Santos, M.R.S. Silva, M.R.D. Bomio, E. Longo, C.A. Paskocimas, F. V. Motta, TiO2/PDMS nanocomposites for use on self-cleaning surfaces, Surface and Coatings Technology. 239 (2014) 16-19. doi:10.1016/j.surfcoat.2013.11.009.

[14] A.J. Wang, K.-S. Liao, S. Maharjan, Z. Zhu, B. Mcelhenny, J. Bao, S.A. Curran, Percolating Conductive Networks in Multiwall Carbon Nanotube- Filled Polymeric Nanocomposites : Towards Scalable High- Conductivity Applications of Disordered Systems, Nanoscale. 11 (2019) 8565. doi:10.1039/x0xx00000x.

[15] S. Curran, K.-S. Liao, K. Barton, Self-cleaning coatings and methods for making same, U.S. Patent 10,266,702, 2019.

[16] C.R. Crick, J.C. Bear, A. Kafizas, I.P. Parkin, Superhydrophobic photocatalytic surfaces 
through direct incorporation of titania nanoparticles into a polymer matrix by aerosol assisted chemical vapor deposition, Advanced Materials. 24 (2012) 3505-3508. doi:10.1002/adma.201201239.

[17] N. Zhao, F. Shi, Z. Wang, X. Zhang, Combining layer-by-layer assembly with electrodeposition of silver aggregates for fabricating superhydrophobic surfaces, Langmuir. 21 (2005) 4713-4716. doi:10.1021/la0469194.

[18] B. Bhushan, Y.C. Jung, K. Koch, Micro-, nano- And hierarchical structures for superhydrophobicity, self-cleaning and low adhesion, Philosophical Transactions of the Royal Society A: Mathematical, Physical and Engineering Sciences. 367 (2009) 16311672. doi:10.1098/rsta.2009.0014.

[19] M. Ma, R.M. Hill, Superhydrophobic surfaces, Current Opinion in Colloid \& Interface Science. 11 (2006) 193-202. doi:10.1016/j.cocis.2006.06.002.

[20] G.V. Samsonov, Mechanical Properties of the Elements, in: Handbook of the Physicochemical Properties of the Elements, Springer, New York, 1968: p. 432. doi:10.1007/978-1-4684-6066-7.

[21] S. Curran, N. Alley, K.-S. Liao, A. Haldar, Fixed and portable coating apparatuses and methods, US20150064340A1, 2014. doi:10.1037/t24245-000.

[22] T. Sarver, A. Al-Qaraghuli, L.L. Kazmerski, A comprehensive review of the impact of dust on the use of solar energy: History, investigations, results, literature, and mitigation approaches, Renewable and Sustainable Energy Reviews. 22 (2013) 698-733. doi:10.1016/j.rser.2012.12.065.

[23] A. Sayyah, M.N. Horenstein, M.K. Mazumder, Energy yield loss caused by dust deposition on photovoltaic panels, Solar Energy. 107 (2014) 576-604. doi:10.1016/j.solener.2014.05.030.

[24] B. Kaynak, C. Alpan, M. Kratzer, C. Ganser, C. Teichert, W. Kern, Anti-adhesive layers 
on stainless steel using thermally stable dipodal perfluoroalkyl silanes, Applied Surface Science. 416 (2017) 824-833. doi:10.1016/j.apsusc.2017.04.197. 